\title{
Penerapan Arsitektur Tropis dalam Era New Normal
}

\author{
Dian Kusumowardani ${ }^{1}$ \\ ${ }^{1}$ Program Studi Arsitektur, Institut Teknologi Budi Utomo \\ 1.dkusumowardani@yahoo.com
}

\begin{abstract}
ABSTRAK
Seiring dengan perkembangan teknologi di dunia saat ini yang memasuki Revolusi Industri 4.0 dan pandemik yang melanda dunia telah mengubah pola hidup manusia, menuntut manusia untuk menggunakan teknologi dalam mewujudkan manusia yang berkehidupan lebih sehat, terampil dan lebih cerdas.

Kekayaan arsitektur tropis pada bangunan tradisional di Indonesia menjadi hal yang sangat menarik dalam hubungannya dengan modernisasi dan adaptasi dari masyarakat tradisional menuju masyarakat modern.

Masyarakat Indonesia tengah mengalami proses adaptasi budaya baik budaya fisik maupun non fisik dengan perkembangan ilmu pengetahuan serta kemajuan teknologi melalui penggunaan bahan bangunan dan teknologi di dunia sejalan dengan perkembangan teknologi terutama teknologi yang dapat diterapkan pada sebuah bangunan.

Era New Normal dengan tuntutan orientasi pada kesehatan dan kenyamanan penghuni dan pengguna bangunan kesadaran akan tuntutan ini membingkai semangat pembangunan arsitektur yang mampu beradaptasi dan berkelanjutan, yaitu beradaptasi dengan modernitas tanpa kehilangan kearifan lokal serta kesesuaian terhadap kondisi iklim Indonesia dengan secara bijaksana.sebagai upaya untuk menyelamatkan bumi.
\end{abstract}

Kata kunci: arsitektur, tropis, teknologi, era, new normal

\section{ABSTRACT}

Along with the development of technology, the world has entered the fourth industrial revolution. Especially with the addition of the pandemic, the "New Normal" lifestyle that has been enforced on us has changed our lives fundamentally to use technology to be more safe and smarter in our interaction to live a much healthier life.

With that, the ingrained tropical style architecture that's found widespread across Indonesia has become an interesting trait, seeing that it sparked interest within the modernising public.

Many of Indonesians are in the midst of adapting to new cultures. Both in the physical sense and the non-physical sense with the progression sciences and the continuing development of technology, especially through the application and usage of technology within the construction process of buildings in the fourth industrial revolution.

This new era demands that health and medical aspects should also be considered as well as the consumer's comfortability. With this change, it also pushes architects to be more creative and open towards modernity without the expulsion and exclusion of traditional aspects that's best suited for the tropical climate with a wise intent to preserve earth and its beauty

\section{PENDAHULUAN}

\section{A. LATAR BELKANG}

Arsitektur tropis pada bangunan tradisional Indonesia, merujuk pada sebuah gaya arsitektur khas kawasan tropis yang dekat dengan garis khatulistiwa terkadang matahari bersinar sangat terik dan membuat udara begitu panas, namun di waktu lain, hujan deras berkepanjangan membuat cuaca begitu dingin dan terkadang menyebabkan banjir. Oleh 
karena itu, desain di kawasan tropis memiliki desain khas dengan keunikannya tersendiri untuk menyiasati cuaca panas terik dan curah hujan tinggi.

Istilah tropis merujuk pada wilayah yang secara geografis memiliki dua musim saja, yaitu musim hujan dan musim panas. Iklim tropis menyebabkan panas matahari terik, tingkat kelembapan udara yang cukup tinggi, curah hujan tinggi, hingga pergerakan angin yang tak terduga. Oleh karena itu, kawasan beriklim tropis membutuhkan gaya arsitekturnya tersendiri untuk menyiasati problematika cuaca yang ada. Gaya arsitektur tropis menawarkan solusi untuk beradaptasi dengan pengaruh cuaca tropis dan penggunaan penghawaan alami dengan membuat sirkulasi udara pada desain bangunan untuk memperoleh penghawaan bangunan yang baik.

\section{B. PERMASALAHAN}

Bangunan pada Era New Normal saat ini dituntut untuk memiliki tingkat adaptasi yang baik agar hunian nyaman untuk ditinggali. Manfaat arsitektur tropis bagi hunian di antaranya dapat mencegah hujan masuk, menjaga kelembapan udara, dan membuat udara tetap nyaman.Selain itu, elemen interior dan eksterior pada bangunaan bergaya tropis pun telah dirancang agar tetap membuat rumah nyaman dan beradaptasi dengan cuaca yang ada.

\section{METODE PENELITIAN}

Metode dalam penulisan jurnal ini menggunakan deskriptif kualitatif dengan melakukan analisis terhadap data literature melalui kajian pustaka dengan mengumpulkan data-data dari sumber primer.

\section{HASIL PENELITIAN DAN PEMBAHASAN}

Ciri bangunan Arsitektur Tropis

Ciri khas dari rumah dengan gaya arsitektur tropis memiliki ciri yang sangat menonjol dan sangat berbeda dengan arsitektur bangunan lainnya. dengan memperhatikan ciri-ciri umum di bawah ini :

\section{Atap Segitiga}

Ciri atau karakteristik yang paling menonjol dari bangunan tropis adalah penggunaan atap berbentuk segitiga dengan kemiringan yang curam. Bentuk atap segitiga yang biasa digunakan adalah atap limasan, atap pelana, atap kerucut, ataupun atap segitiga tumpang.

Atap segitiga secara langsung meciptakan ruang di bawahnya sebagai sistem isolasi panas sehingga suhu panas tak langsung masuk ke ruangan. Atap segitiga ini merupakan pilihan terbaik untuk mencegah panas, sehingga tak heran model atap ini digunakan di hampir seluruh bangunan di Indonesia.

\section{Teritisan Atap yang Lebar}

Ciri lain yang cukup kentara dari rumah bergaya arsitektur tropis adalah adanya teritisan atau overstek atap yang lebar. Teritisan atau overstek adalah bagian atap yang menonjol keluar atau melebihi ukuran bangunan.

\section{Memiliki Shading Bangunan}

Selain menggunakan teritisan, bangunan bergaya tropis juga sering mencegah panas atau air hujan dengan menggunakan shading atau pembayang. Shading dapat dibuat dari berbagai bahan dari mulai tirai bambu, tirai kain, gorden, ataupun roller blind. Penggunaan shading sangat mudah karena hanya tinggal dipasangkan pada pinggiran ruang terbuka di rumah atau di sekitar jendela. 


\section{Penataan Layout Bangunan}

Penataan layout bangunan bergaya arsitektur tropis biasanya sangat memperhatikan arah datangnya sinar matahari. Hal ini akan sangat berpengaruh pada penataan desain lemari karena bangunan tropis biasanya tidak membuat jendela di arah timur dan barat. Arah timur dan barat merupakan arah dengan sorotan matahari tinggi sehingga pemasangan jendela di kedua sisi tersebut akan membuat suhu ruangan sangat panas. Jendela dan ventilasi di arah utara dan selatan agar tidak terkena cahaya matahari langsung

\section{Menerapkan Sirkulasi Silang}

Aspek arsitektur tropis yang tak kalah pentingnya juga terdapat pada bagian ventilasi udara yang biasa menggunakan sistem sirkulasi silang. Penggunaan sistem sirkulasi silang akan membuat pergantian udara di ruangan lebih stabil sehingga kualitas udara lebih baik. Selain menggunakan sistem sirkulasi silang, bangunan bergaya arsitektur tropis juga biasanya memasang ventilasi dalam jumlah yang cukup banyak.

Konstruksi bangunan tidak terkecuali bangunan dengan gaya arsitektur tropis di Indonesia saat ini harus siap terhadap perubahan mendasar yang memungkinkan produktivitas, keselamatan, peningkatan proses dengan alat-alat yang menerapkan teknologi baru pada bangunan seperti penerapan Internet of Things (IoT), digitalisasi dan penggunaan Panel Surya memungkinkan terwujudnya kenyamanan pada bangunan arstektur tropis di Indonesia dengan biaya yang efektif.

Data bangunan menjadi asset penting dalam pengambilan keputusan dalam penerapan Internet of Things (IoT), digitalisasi dan penggunaan Panel Surya pada sebuah bangunan dengan Arsitektur Tropis di Indonesia. Secara umum produktivitas, pemeliharaan, keamanan dan keselamatan penghuni serta pengguna bangunan menjadi pendorong utama adopsi IoT, digitalisasi dan Panel Surya pada Industri Konstruksi di Era Revolusi Industri 4.0 dan New Normal.

\section{Produktivitas}

Sektor Konstruksi dikondisikan oleh waktu dan target hal ini untuk menghindari adanya peningkatan anggaran. IoT, digitalisasi dan Panel Surya dapat memungkinkan lebih banyak efisiensi sehingga dapat meningkatkan produktivitas.

\section{Pemeliharaan}

Konsumsi daya pada masa layanan bangunan untuk dapat memenuhi tuntutan aktivitas penghuni dan penggunanya akan menghasilkan pemborosan jika tidak dikelola secara aktif dan akan berdampak pada kelangsungan hidup mahluk hidup di Bumi.

Melalui ketersediaan informasi real tima, dimungkinkan untuk mengetahui status setiap asset untuk menjadwalkan penghentian perawatan atau pengisian sumber energi pada sebuah bangunan dan dapat mematikan peralatan yang idle (tidak dalam penggunaan) secara otomatis melalui sensor-sensor yang dipasang dalam sebuah bangunan bahkan lebih jauh lagi sensor medan dapat dimanfaatkan untuk memfungsikan seperti kapan fungsi bukaan pada bangunan tropis harus digunakan untuk mengantisipasi iklim tropis saat musim panas dan kapan harus memfungsikan fungsi-fungsi bangunan saat musim hujan, kesesuaian tehadap konsidi suhu/kelembaban, kualitas udara/lingkungan bangunan untuk dapat mengatasi masalah, kerusakan. 


\section{Keselamatan dan Keamanaan}

Dengan menggunakan teknologi bangunan masalah keselamatan dan keamanan pengguna dan penghuni bangunan arsitektur tropis di Indonesia dapat diselesaikan karena sensor akan memberi informasi pada pengguna bangunan tersebut hal ini dapat menjadi lebih prediktif terhadap masalah-masalah yang dapat menyebabkan insiden keselamatan dan keamanan pengguna bangunan.

\section{KESIMPULAN}

Seiring dengan kemajuan teknologi dan kondisi pandemik yang melanda dunia telah merubah interaksi social manusia secara tatap muka akan bergeser menyesuaikan dengan segala tuntutan pada Era New Normal, yang menuntut akan kenyamanan dan keselamatan pada bangunan dengan gaya arsitektur tropis di Indonesia tuntutan tersebut dapat terpenuhi, melalui penerapan rancangan arsitektur tropis pada sebuah bangunan di Indonesia maka bangunan tersebut akan dapat memenuhi segala tuntutan tersebut sehingga bangunan yang aman nyaman dapat terwujud.

\section{DAFTAR PUSTAKA}

Karyono Tri Harso, 2016, Arsitektur Tropis bentuk teknologi, Kenyamanan dan penggunaan energy, Erlangga

Kindangen Jefri I, 2017, Pendinginan pasif untuk arsitektur tropis lembab

Nugroho Agung Murti , 2018, Arsitektur Tropis Nusantara, UB Press

Karyono Tri Harso, 2013,Arsitektur dan Kota Tropis dunia Ke 3, Rajawali Pers

Van Dullmen C.J, 2018, Arsitektur Tropis modern, Komunitas Bambu

Hindrato Probo, 2017, 37 Konsep Hunian Tropis, Griya Kreasi

Trihanto Bowo, 2018,18 Desain rumah berkonsep tropis modern, Andi 